\title{
Flow Measurement Technologies and Supporting Research in the EMPAS Project
}

\author{
John J. Doherty ${ }^{*}$, David M. Birch ${ }^{\dagger}$, John Chew*, Paul Hayden ${ }^{\S}$ \\ University of Surrey, Guildford, Surrey, GU2 7XH, United Kingdom
}

\begin{abstract}
The EMPAS collaborative project covered development and demonstration of an electric motor powered aero-engine simulator in the QinetiQ 5-metre wind-tunnel. As part of the project, the University of Surrey was responsible for background research and development of various flow measurement and system monitoring technologies, for use in the EMPAS windtunnel tests. Development of an integrated digital pressure rake system is presented, which has enabled assessment of duct flow characteristics and derivation of fan pressure ratio for the EMPAS system. A novel approach based on use of miniature, low cost microphones was developed, which successfully provided in-situ fan RPM measurement and highlighted several promising areas for future monitoring of fan/system health. A 7-hole pressure probe was used to great effect for extensive flow-field surveys, to investigate and validate the aerodynamic flow field effects associated with the aero-engine simulator. Wind-tunnel results from use of the microphone and 7-hole probe systems are analyzed and presented in detail.
\end{abstract}

\section{I.Nomenclature}

$A T I=$ Aerospace Technology Institute

$E M P A S=$ Electric Motor Powered Aero-engine Simulator

$F P R \quad=$ Fan Pressure Ratio

$M \quad=$ freestream Mach number

$R P M \quad=$ Fan speed (Revolutions Per Minute)

TPS $=$ Turbine Powered Simulators

$7 H P=7$ Hole Pressure Probe

$U \quad=$ local flow speed $\left(\left(\mathrm{u}^{2}+\mathrm{v}^{2}+\mathrm{w}^{2}\right)^{0.5}\right)$

$U_{\infty} \quad=$ free stream flow speed

$\beta \quad=$ yaw angle

$f_{b p} \quad=$ blade passing frequency

$u, v, w=$ local flow velocity components along $\mathrm{X}, \mathrm{Y}, \mathrm{Z}$ directions

\section{II.Introduction}

The installation of powered engine simulators, within airframe wind-tunnel testing, is traditionally a costly and complex challenge, which has previously been achieved using turbine powered simulators (TPS), powered by pneumatic or hydraulic supply. The alternative use of an electric motor driven engine simulator can deliver potential benefits, including simplified installation, significantly reduced infrastructure requirements and operating cost savings. Continuing improvements in electric motor technology, particularly in terms of increased power density, led in 2016 to the Electric Motor Powered Aero-engine Simulator (EMPAS) [1,2] project, funding jointly the consortium partners and the UK ATI. The EMPAS consortium consisted of QinetiQ as project leaders, together with Boeing, Collins Aerospace, Ate-AEROTECH and the University of Surrey.

At the end of the EMPAS project in 2019 there was a successful demonstration of the use of a $140 \mathrm{~kW}$ electric motor to power an aero-engine simulator, having a 6.5 inch diameter fan, installed within a wing-pylon model and tested over a 3 week period in the QinetiQ 5-metre low-speed wind-tunnel, as shown in figure 1. An overview of the

\footnotetext{
* Reader, Department of Mechanical Engineering Sciences, Associate Fellow AIAA, John.Doherty@surrey.ac.uk

$\uparrow$ Senior Lecturer, Department of Mechanical Engineering Sciences, Senior Member AIAA.

* Professor of Mechanical Engineering, Department of Mechanical Engineering Sciences.

$\S$ Environmental Flow Research Laboratory (EnFlo), Department of Mechanical Engineering Sciences.
} 
full EMPAS project can be found in references 1 and 2. The design and manufacture of the wind-tunnel model is provided in reference 3, while the full data acquisition system is described in reference 4. During the EMPAS windtunnel test, a new pressure probe traverser was demonstrated by Ate-AEROTECH, as also shown in figure 1 and this is described in reference 4. Finally, a summary of the validation of the full EMPAS system is given in reference 5.

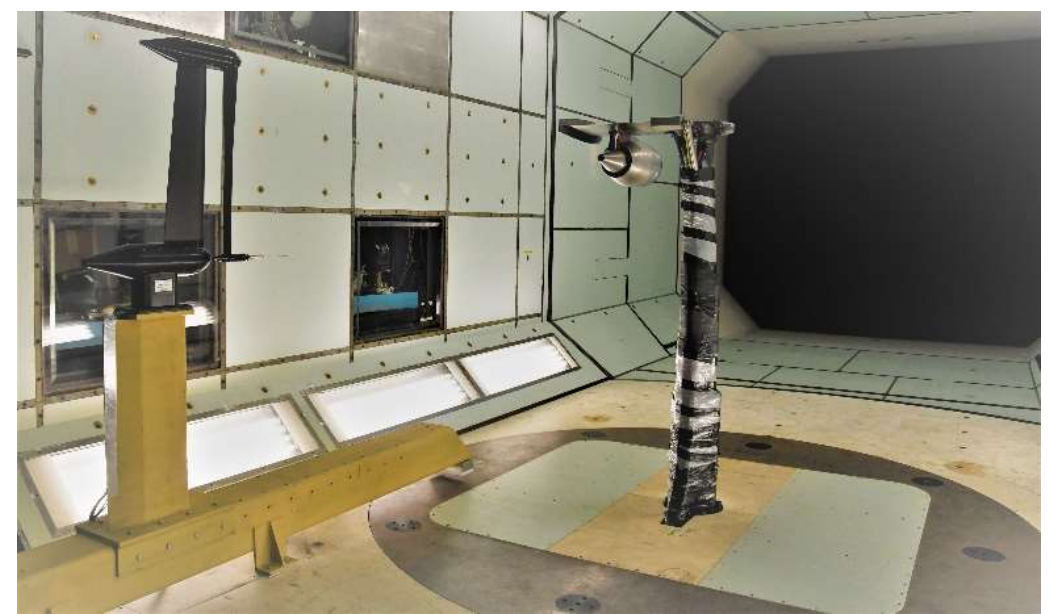

Fig. 1 Electric Motor Powered Aero-engine Simulator (EMPAS) model in QinetiQ 5M wind-tunnel together with Ate-AEROTECH pressure probe traverser.

As part of the EMPAS consortium the University of Surrey was responsible for several supporting research activities and for development of measurement technologies used within the demonstrated EMPAS system. The rest of this paper describes development of pressure and microphone based measurement technologies at Surrey, together with analysis of experimental results from the EMPAS QinetiQ 5-metre wind-tunnel test.

\section{III.Measurement Technologies}

\section{A. Integrated digital pressure rake system}

A bespoke, low cost, pressure rake system has been developed for use within the EMPAS system to enable measurement of fan pressure ratio during testing. The pressure rakes, which are positioned within the duct just downstream of the fan-guide vanes, were required to also fully integrate the associated pressure transducers and microelectronics, to enable digital communication output, reducing the need to extend installation of numerous pressure tubes beyond the nacelle and through the pylon/wing.

The rakes make use of a 7 channel digital pressure measurement system, developed previously by Surrey Sensors [6] and the University of Surrey, as shown in figure 2. Each pressure measurement system incorporates seven Honeywell 5psi board mounted differential pressure sensors, a local air temperature sensor for automated temperature correction, together with onboard inertial positioning ( 3 axis gyro, 3 axis accelerometer) for automated probe alignment and vibration detection. Each system requires a USB cable for digital communication and a reference pressure input tube (a single input tube was daisy-chained to deliver reference pressures to all the rakes). The system can acquire and communicate pressures at up to $1 \mathrm{kHz}$, although during the EMPAS test acquisition rates of $100 \mathrm{~Hz}$ and lower were used.

An integrated rake manifold was designed, which incorporates the flow rake and houses the digital pressure system. The flow rake measures pressures at 7 locations spread across the radius of the duct. The manifold integrates seven individual pressure 'tubes', as shown in figure 3, which connect the rake pressure measurement locations to each of the pressure transducers shown in figure 2 . 


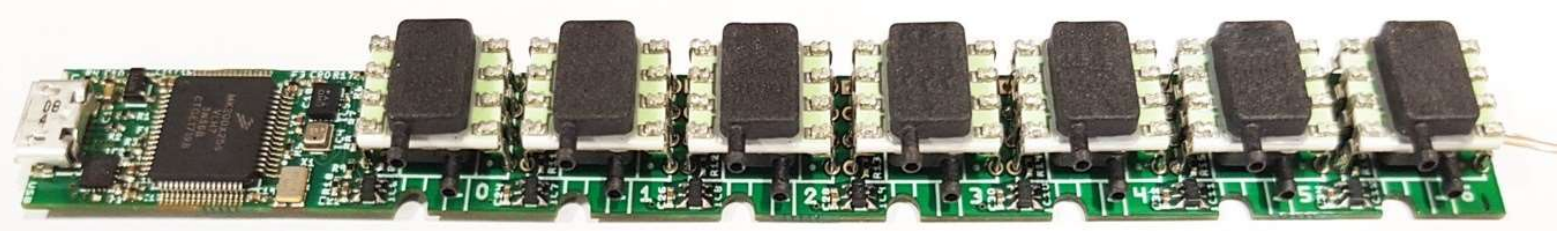

Fig. 2 7-channel digital pressure measurement system.

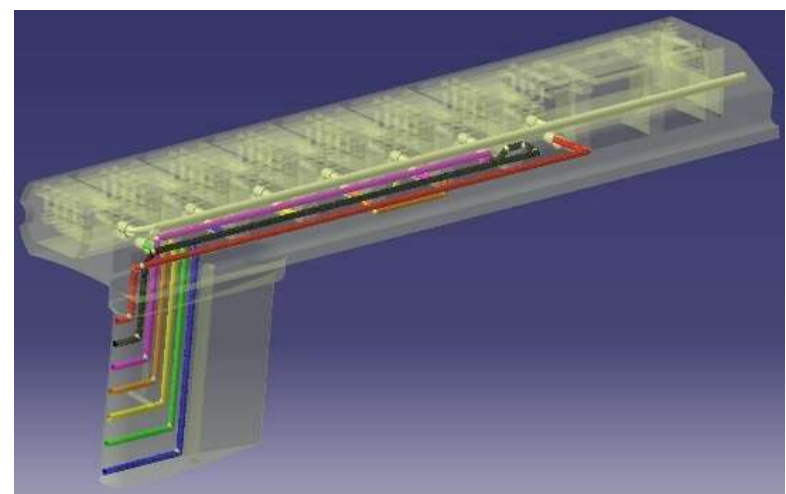

Fig. 3 CAD view of integrated digital pressure rake design, with 7 pressure tubes highlighted.

The rake manifold was manufactured using SLA 3D printing, a material which is similar to acrylic, which was then reinforced with a steel rod through the rake section itself. A fully assembled integrated digital pressure rake is shown in figure 4 . The overall length of the integrated digital pressure rake is $150 \mathrm{~mm}$, including additional room for reference pressure tube and USB connection, with width $30 \mathrm{~mm}$. The rake section protrudes $36 \mathrm{~mm}$ into duct and has a maximum thickness of $6 \mathrm{~mm}$. The $3 \mathrm{D}$ printed internal pressure tubes are of diameter $0.8 \mathrm{~mm}$, which has been found to be suitable for SLA manufacture. These pressure tubes were designed to have near constant length, to cater for potential dynamic pressure measurement.
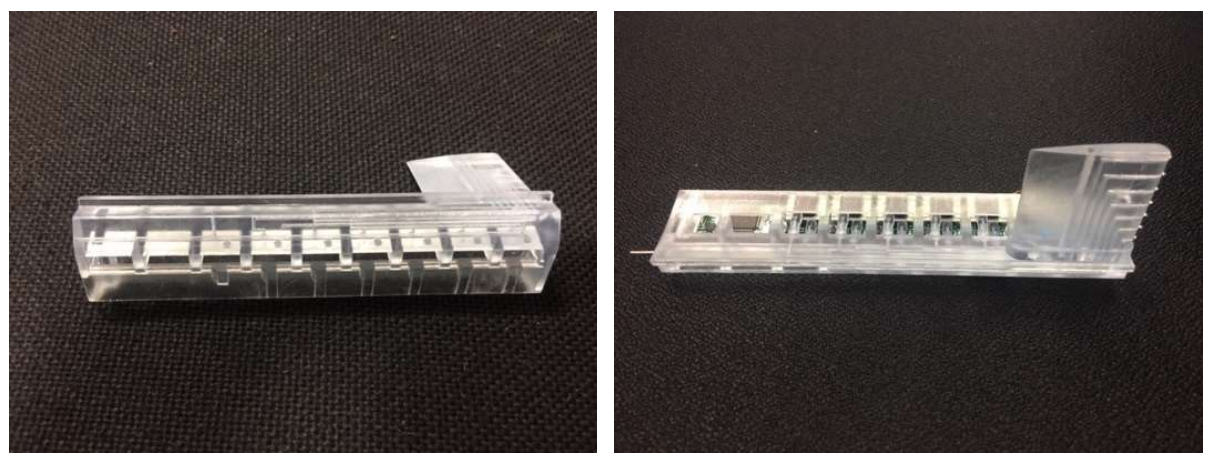

Fig. 4 SLA 3D printed rake manifold with installed digital pressure measurement system.

Four integrated digital pressure rakes were manufactured and installed in the EMPAS system. These were located around the circumference of the EMPAS system as shown in figure 5a, providing a total of 28 independent pressure measurements to investigate local flow downstream of the fan and to derive an area weighted fan pressure ratio (FPR). Previous wind tunnel studies completed at the University of Surrey, for electric ducted fan configurations, have investigated how the local pressure, measured within a duct, can vary at differing locations around the duct. In particular, the connection of the EMPAS nacelle to the pylon results in a bifurcation, meaning the duct flow will not be fully axisymmetric. To allow this to be investigated, the EMPAS model was manufactured with additional locations around the circumference to allow the rakes to be repositioned. The nacelle has an instrumentation bay which allows 
full access for installation and repositioning of the rakes during testing, by removing the central nacelle outer covers, as shown in figure $5 \mathrm{~b}$.

a)

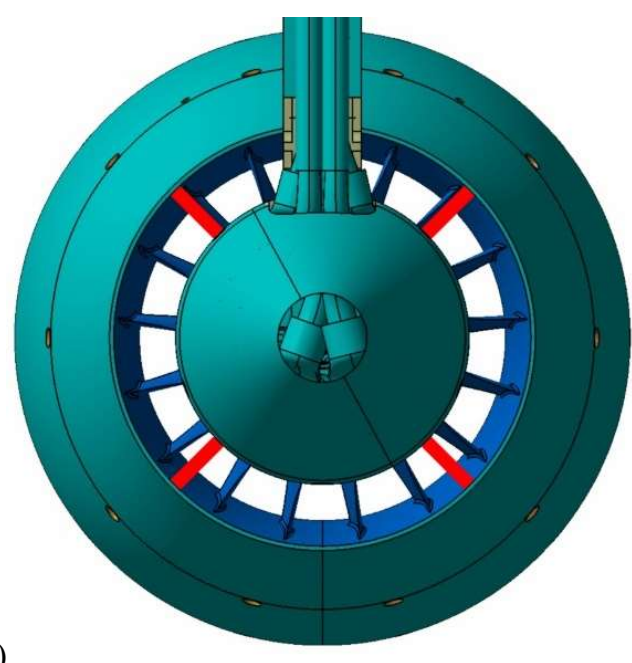

b)

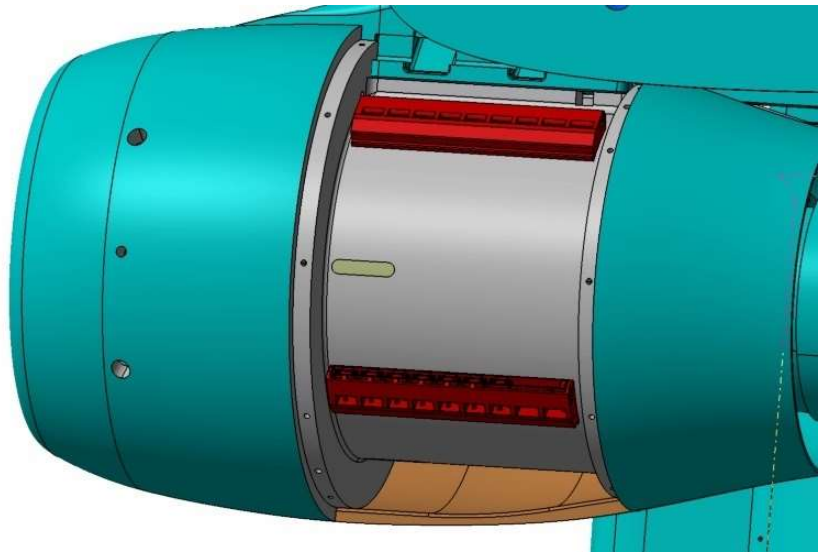

Fig. 5 Pressure rake installation shown in red for EMPAS CAD a) circumferential location of rakes in duct and b) nacelle instrumentation bay.

Figure 6 shows a cross section through the nacelle and a rake, to further highlight both the location of the pressure measurement stations across the duct and the ample volume available within the instrumentation bay.

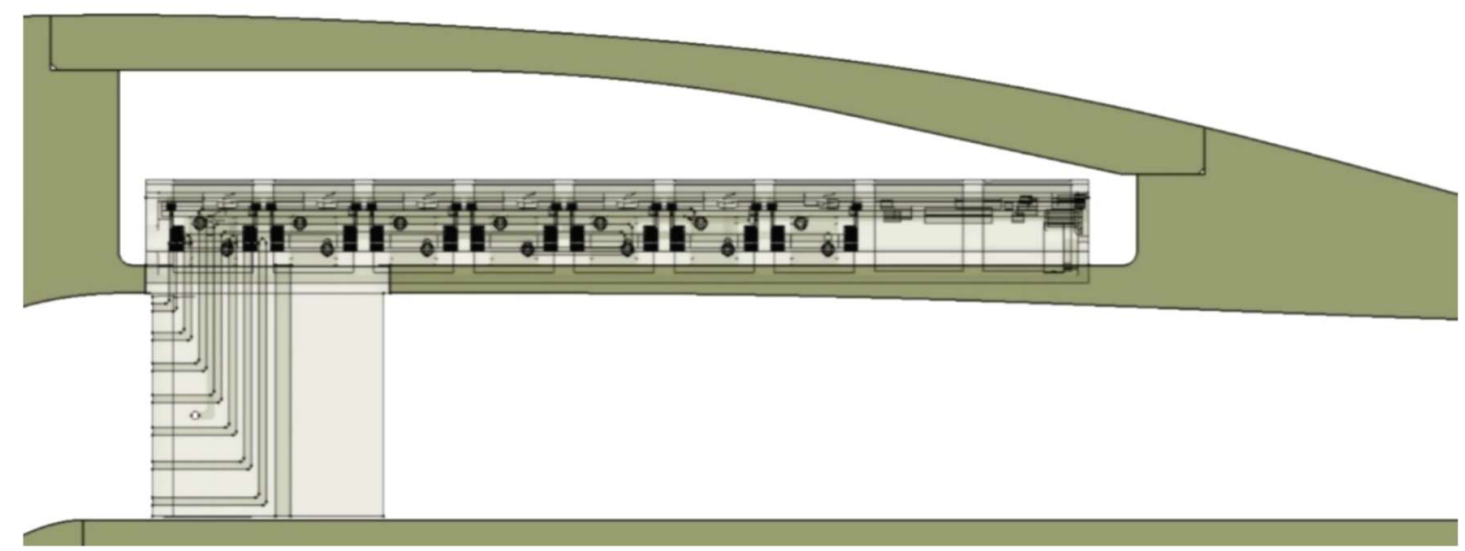

Fig. 6 CAD cross-section through the nacelle, instrumentation bay and rake.

Following loss of a key member of staff at Surrey, Ate-AEROTECH were asked to step in at a late stage to implement a communications process between the integrated digital pressure rakes and their EMPAS data acquisition and control system. This utilized a direct USB connection to a mini-PC located under the tunnel floor, for each of the four rakes [4]. In addition, Ate-AEROTECH developed a new USB software driver, which in turn allowed live streaming of rake pressures to the EMPAS data acquisition and control system.

\section{B. Microphone Based Fan Monitoring}

Previous experimental studies completed at Surrey have investigated the use of miniature, very low cost, microphones as an effective and simple means for RPM measurement in electric ducted fan aerodynamics research. Figure 7 shows an early experimental study at Surrey, using a low RPM computer fan and two electret condenser 
mono microphones, located at differing distances from the fan leading edge. Locating a microphone close to the rotating fan enables detection of the pressure variation, associated with each passing blade, within the measured signal. For low speed fans at least, this can be achieved using standard audio connections and readily available signal processing software. A signal peak, corresponding to the blade passing frequency $\left(f_{b p}\right)$, can then be used to provide an instantaneous measure of fan speed RPM, based upon knowledge of the number of fan blades $n$, as presented in Equation 1:

$$
R P M=\frac{60 f_{b p}}{n}
$$

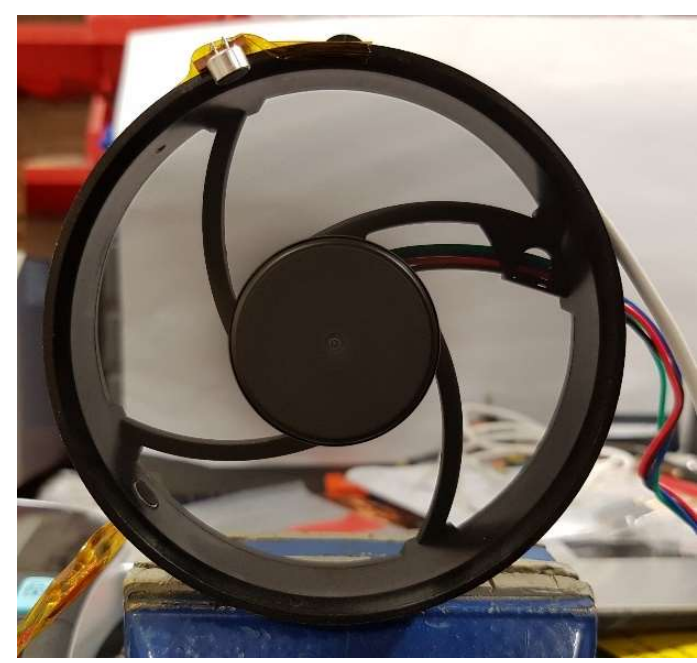

Fig. 7 An early Surrey investigation of fan RPM measurement using two microphones at differing locations relative to the rotating fan.

In addition to direct RPM measurement, previous research has also highlighted the potential for microphones to detect other pressure-based effects. Since the microphone detects each blade passing event, variations in the response from individual blades can be compared, as a basis for assessing the uniformity (health) of the fan. For example, fan/blade vibration or aerodynamic separation effects could each lead to elevated, broadband noise in the signal power spectra, while a damaged blade would be evidenced by a strong amplitude at a frequency of $f_{p b} / n$.

Within the EMPAS project it was decided to integrate microphones into the model, primarily to have an in-situ direct means to measure fan RPM, in parallel to the RPM output from the motor controller. In addition, it also provided a means to investigate the use of a microphone as a future safety system, to potentially identify any variation in fan behavior which could be a sign of vibration or even damage to a blade.

Two 6mm diameter mono electret condenser microphones were integrated into the EMPAS design, flush mounted on the upper and lower inner surfaces of the duct inlet. These microphones are very low cost $(<\mathrm{US} \$ 25)$ but have been found to be reasonably robust. The location of the microphones, relative to the fan, was chosen based upon previous tests at Surrey. The lower duct microphone is shown in figure 8, with a gap of $1 \mathrm{~mm}$ between the edge of the microphone body and the fan leading edge. 

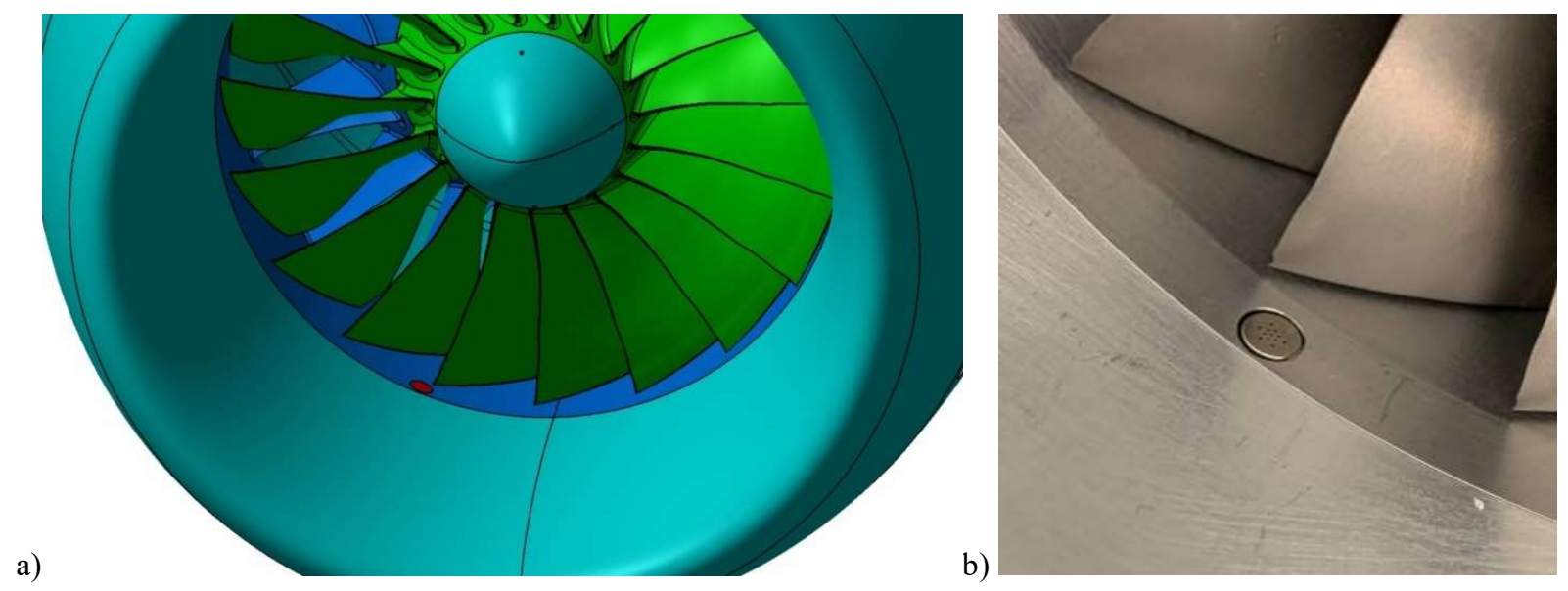

Fig. 8 Detail of lower microphone installation a) CAD view of lower nacelle with microphone location shown in red and b) zoomed in view of microphone installed in EMPAS wind tunnel model

A small channel within the model allows the microphone wires to be fed into the instrumentation bay shown earlier in figure 5. The output from each mono microphone was combined to create left/right channels for a stereo signal, and this was then connected to the audio jack of a Windows laptop located under the tunnel floor. The laptop was networked to the tunnel test control room, meaning the microphone signal could be monitored and recording during the wind-tunnel tests. As discussed earlier, the peak signal strength detected is usually associated with the blade passing frequency, so then fan RPM predicted from the microphone could be compared with the RPM read out from the motor controller. Subsequent post-processing of the data from the wind-tunnel tests has been completed using Matlab and results will be presented later in the paper.

\section{Integrated digital 7-Hole Probe System}

A fully integrated digital 7-hole probe was provided by University of Surrey for use within the EMPAS test. The probe is a customized Surrey Sensors ID7HP-series probe, with a full-scale range of 5psi and a total error band of approximately $0.25 \%$ FS [6]. The 7HP uses the same 7-channel digital pressure measurement system as used for the rakes and shown earlier in figure 2 and can measure pressures at up to $1 \mathrm{kHz}$. The complete probe is shown in figure 9 and includes a low-profile, in-line sensor package measuring $150 \mathrm{~mm}$ in length and $18 \mathrm{~mm}$ in diameter. The steel sting and tip diameter is $3.7 \mathrm{~mm}$ and has angular measurement range up to $\pm 45 \mathrm{deg}$. The on-board sensor package also measures ambient temperature, humidity and absolute static pressure, together with signals from an inertial measurement unit (IMU) for alignment and vibration warning.
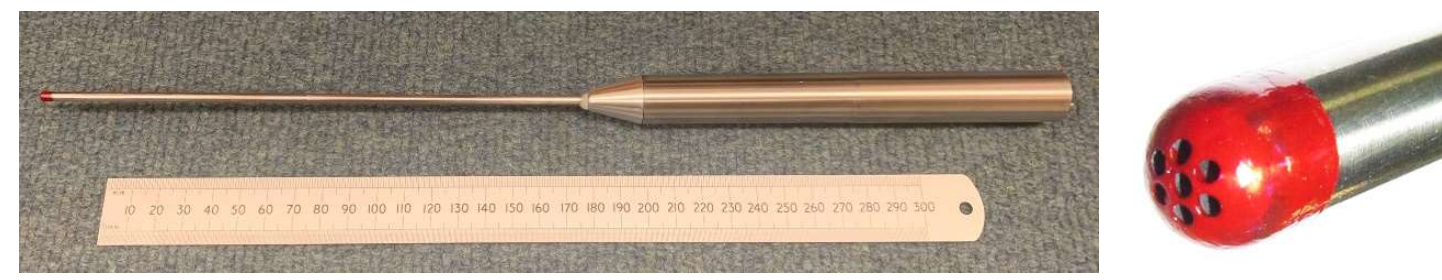

Fig. 9 Integrated digital 7-hole probe with detail of probe tip (diameter $3.7 \mathrm{~mm}$ ).

The 7HP probe was mounted onto the Ate-AEROTECH pressure probe traverser as shown in figure 1 and used to investigate the flow field downstream of the EMPAS system. Data from the 7HP was recorded by the EMPAS data acquisition system at a sample rate of $100 \mathrm{~Hz}$ [4].

The 7HP had not been calibrated prior to the EMPAS test, so translation from the 7 pressures values to flow velocity components $(u, v, w)$ was not possible at the time of the test. However, following on from the EMPAS project, the probe has subsequently been initially calibrated in a low-speed tunnel at Surrey using an automated calibration technique [7,8]. This calibration allows individual velocity components to be determined in hindsight from the EMPAS data. As the calibration is currently based on incompressible flow assumptions, the peak flow speed will be slightly over-estimated in the highest Mach number flow regions considered here. 
Flow field surveys were completed for a range of tunnel and fan RPM operating conditions. The location and extent of the surveys are shown in figure 10 , corresponding to $57 \mathrm{~mm}, 700 \mathrm{~mm}$ and $1540 \mathrm{~mm}$ aft from the end of the motor tail cone. The surveys were completed as continuous motion traverses, at a speed of up to $20 \mathrm{~mm} / \mathrm{s}$, with the $7 \mathrm{HP}$ measuring data at $100 \mathrm{~Hz}$. The survey region was centered around the approximate centerline of the nacelle and consisted of 16 outward/inward spokes, as will be shown later.
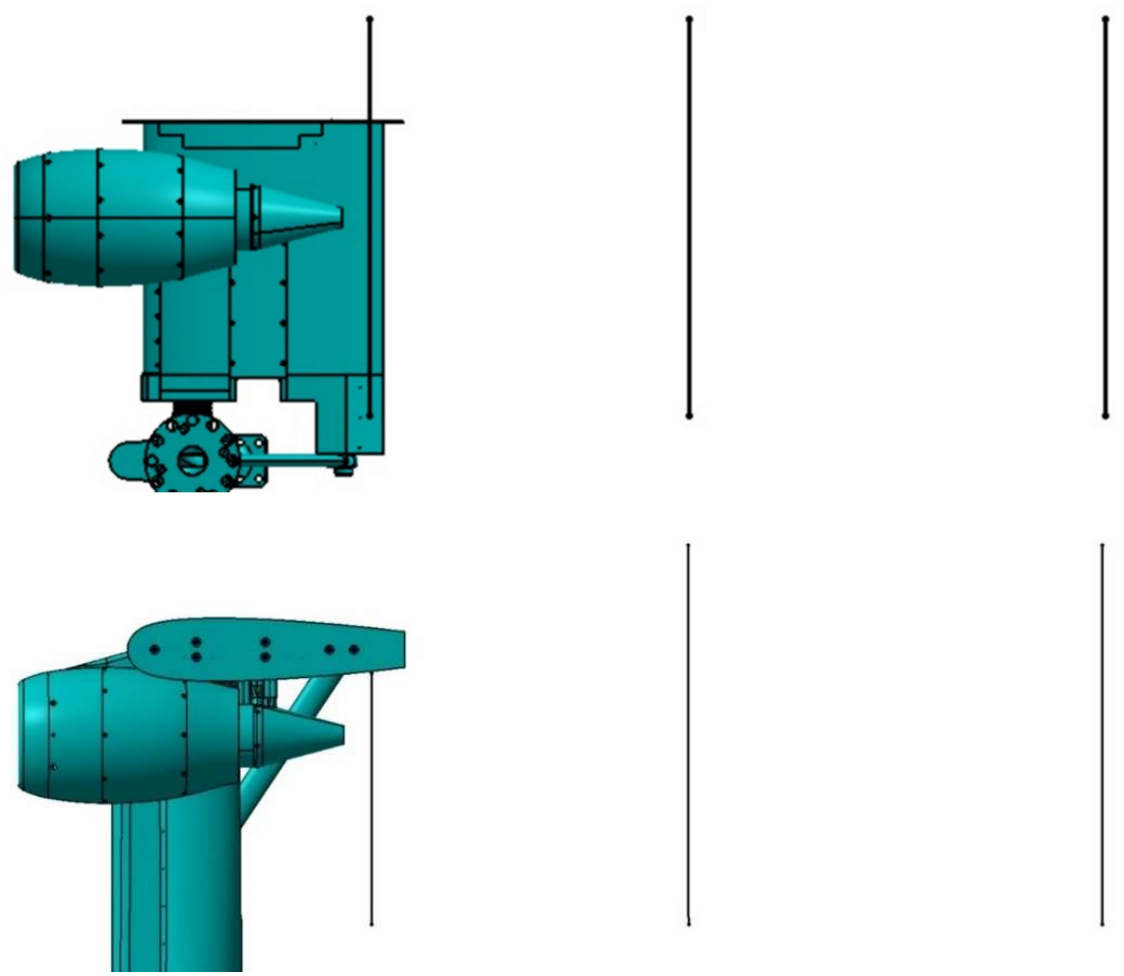

Fig. 10 7HP flow survey location and extent corresponding to $57 \mathrm{~mm}, 700 \mathrm{~mm}$ and $1540 \mathrm{~mm}$ aft from the end of the motor tail cone.

\section{IV.Results}

\section{A. Integrated digital pressure rake system}

Presentation of fan pressure ratio results for the EMPAS system, derived from the use of the pressure rakes during wind-tunnel testing, can be found in reference [5]. Rake pressures were measured over the full range of operating conditions for the EMPAS system, up to an RPM of 42,000 which corresponds to a peak value of FPR=1.4, in line with design expectations. Reference 5 presents the variation of rake pressures in the radial direction across the duct, showing reasonably uniform flow quality over the full range of FPR. Results are also presented for pressure variation around the duct circumference, showing a small but clear trend against circumferential position, which will be associated with the presence of the duct bifurcation as discussed earlier.

During the EMPAS wind-tunnel test there were a variety of communication issues that arose between the rakes and the data acquisition system [5]. As indicated earlier, it had been necessary to implement an alternative communication process at a very late stage, which meant little testing could be completed ahead of the EMPAS windtunnel test. The exact cause of these communications issues is uncertain and further investigation is required. It is possible that a lack of time for properly testing the new communications process, together with the proximity of the USB cables to the motor electrical supply cables within the model mounting strut, may both be contributing factors. 
However, consequently it was not possible to exploit the capability of the rakes to measure duct pressures at high sampling rates, hence no further analysis of duct flow quality will be presented here.

\section{B. Microphone Based Fan Monitoring}

As described in references 2-5, the EMPAS system was tested over a wide range of RPM and wind-tunnel operating conditions. However, certain RPM values were avoided, based on potential fan critical speeds which could lead to fan vibration/resonance. These predicted critical speeds are listed below in Table 1 [3,5]. During the EMPAS tests the fan was not operated continuously close to these critical regions, but rather was driven quickly through these regions.

\begin{tabular}{cc}
$\begin{array}{c}\text { Table } 1 \\
\text { Critical Region }\end{array}$ & $\begin{array}{c}\text { Potential Fan Critical Speed Conditions } \\
\text { Critical Speed (RPM) }\end{array}$ \\
\hline 1 & 17305 \\
2 & 22176 \\
3 & 31399 \\
\hline
\end{tabular}

For the majority of the duration of the EMPAS test, the fan was operated at constant RPM conditions, to provide the time taken to complete lengthy flow field surveys described later. In order to investigate whether the microphones can identify any variation in fan behavior, which could be a sign of vibration, the analysis of microphone data is therefore primarily focused on periods of acceleration or deceleration of the fan, which include the fan passing through these critical speed regions.

Data from the microphone is presented for short periods taken from three EMPAS run cases as listed in Table 2. These runs correspond to differing tunnel operating conditions to assess whether the freestream Mach number has an influence on the capability of the microphones. RUN094 and RUN112 correspond to the fan starting from stationary and accelerating up to a target fan speed. RUN071 corresponds to the situation where the fan was decelerated back to 0 at the end of a test run. Each case corresponds to approximately 20-30 seconds of recorded measurements. Only data from one microphone is presented, since the both measurements are the same but out of phase by $180^{\circ}$ due to there being an odd number $(n=19)$ of fan blades.

\begin{tabular}{ccccc} 
Case & Table 2 & Microphone Data Analysis Cases & \\
& Freestream $M$ & $\begin{array}{c}\text { Start RPM } \\
\text { (microphone) }\end{array}$ & $\begin{array}{c}\text { End RPM } \\
\text { (microphone) }\end{array}$ & $\begin{array}{c}\text { RPM } \\
\text { (controller) }\end{array}$ \\
\hline RUN094 & 0.1 & 0 & 39257 & 39203 \\
RUN071 & 0.0 & 33829 & 0 & 33783 \\
RUN112 & 0.3 & 0 & 36198 & 36188 \\
\hline
\end{tabular}

The recorded data is presented using a spectrogram which highlights the variation of signal strength against frequency and time. Figure 11 shows the result for RUN094, where the fan is started at approximately $t=1 \mathrm{~s}$ and is accelerated linearly by the motor controller, reaching its target speed at approximately $t=21 \mathrm{~s}$. The diagonal red line shows the strongest signal detected by the microphone and corresponds to the blade passing frequency. Using equation 1 , with $n=19$, the fan RPM can be determined against time and is found to reach a maximum value of 39257RPM as shown in Table 2. The value of the target RPM output from the motor controller is also listed in Table 2 and good agreement between the two measurement approaches can be seen. Figure 12 shows the result from RUN071, where the fan is initially operating at about 33783RPM according to the motor controller, but is then decelerated linearly to rest. Again the strongest signal is shown by the red diagonal line, corresponding to the blade passing frequency. For this case, prior to deceleration, the fan speed is found to be 33829RPM based on the microphone data, which again shows good agreement with the motor controller in Table 2.

Figures 11 and 12 show various additional features. The 18 lighter diagonal lines below the strongest signal represent individual 'engine orders', as used within Campbell diagram analysis of fan vibration characteristics to determine critical speed conditions. For the EMPAS fan with 19 blades, these engine orders represent frequencies associated with $1,2,3, \ldots .18$ excitations per RPM, with 19 excitations per RPM corresponding to the blade passing frequency. The short regions of horizontal lines at the start of acceleration in figure 11 and at the end of deceleration in figure 12, have been determined to primarily correspond to the natural 'ringing' frequencies of the fan, by comparison to results from a fan tap test (in which the fan is struck by a small hammer). The lowest frequency horizontal lines, which are present before the fan starts in figure 11, are associated with background noise resulting from the tunnel operation. For example, an oil pump was determined to be the source for a signal at $320 \mathrm{~Hz}$. Finally, 
the downward diagonal lines are non-physical and likely the result of biasing due to the presence of very high frequency harmonics and the limited frequency measurement range associated with the microphone.

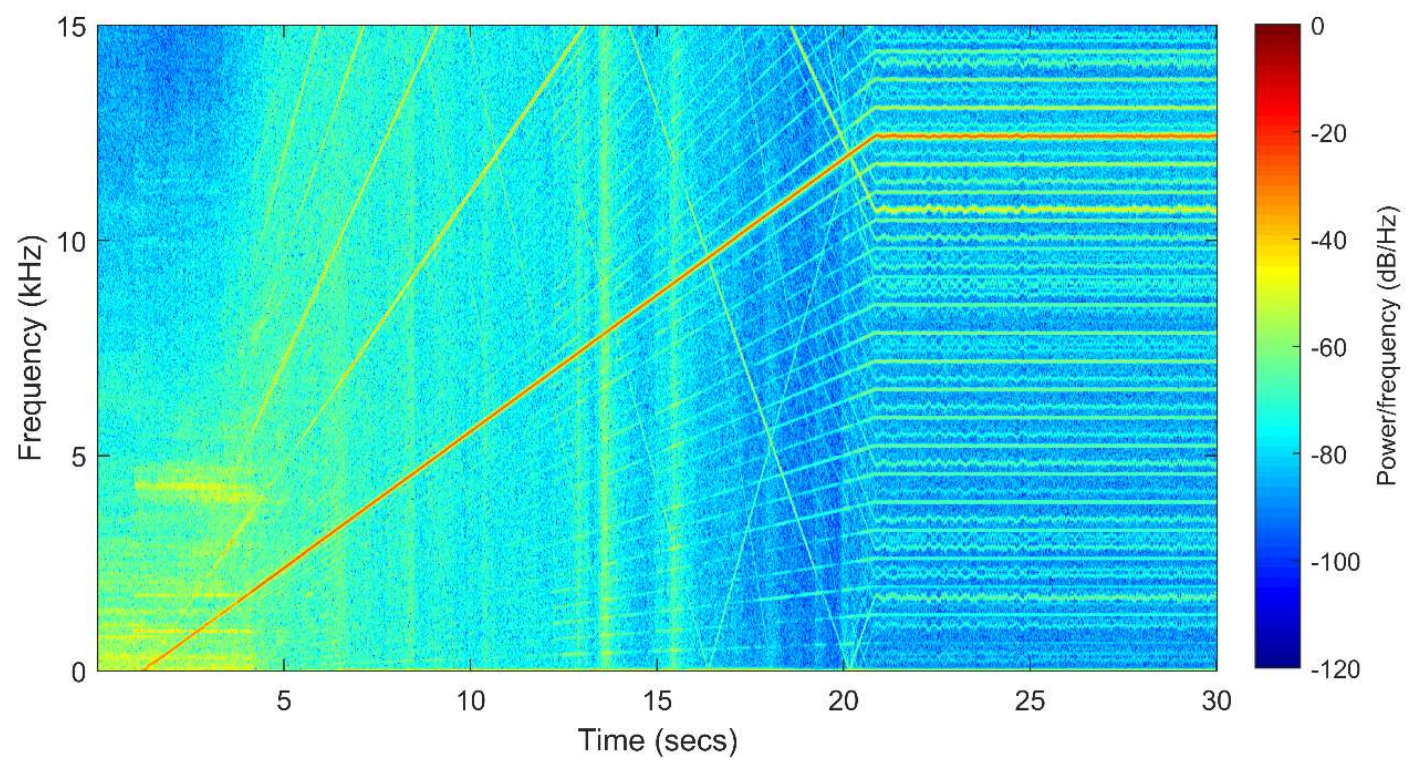

Fig. 11 Microphone spectrogram for RUN094, fan accelerating from rest to 39257 RPM at $M=0.1$.

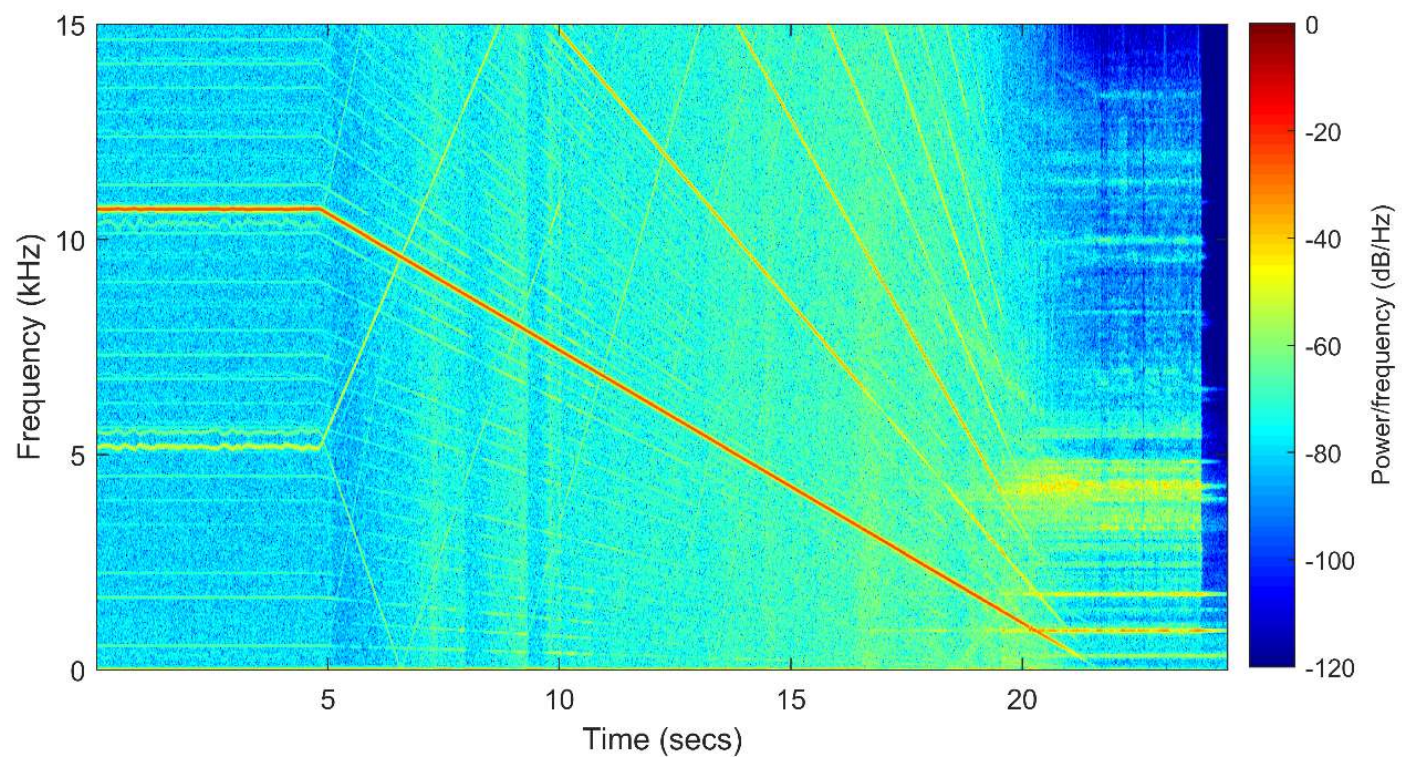

Fig. 12 Microphone spectrogram for RUN071, fan decelerating from 33829 RPM to rest at static conditions.

The spectrograms can be replotted in terms of frequency against the RPM determined from the blade passing frequency analysis. These figures will effectively provide a Campbell diagram for the fan and only the region of acceleration or deceleration will be seen. Figure 13 shows the microphone spectrograms against RPM for the three cases from Table 2. Recalling the critical speeds listed in Table 1, there are no obvious signs of stronger signals around $17 \mathrm{kHz}, 22 \mathrm{kHz}$ or $31 \mathrm{kHz}$. It could be that any fan vibration is too short-lived or too weak to be detected by the microphones, or indeed the potential critical speeds may not occur in practice. However, the microphone data does 
show clear vertical bands where signal strength is increased over all frequencies, particularly around 25000RPM and 28000RPM. These features have been found to occur in a highly repeatable manner for all microphone datasets investigated. The exact cause of these bands has not yet been confirmed, but it is most likely they are directly associated with the fan or other connected rotating components in the system. It is noticeable that the strength of the bands is slightly weakened for RUN071 where the fan is decelerating through these RPM regions rather than accelerating. These bands require further investigation.

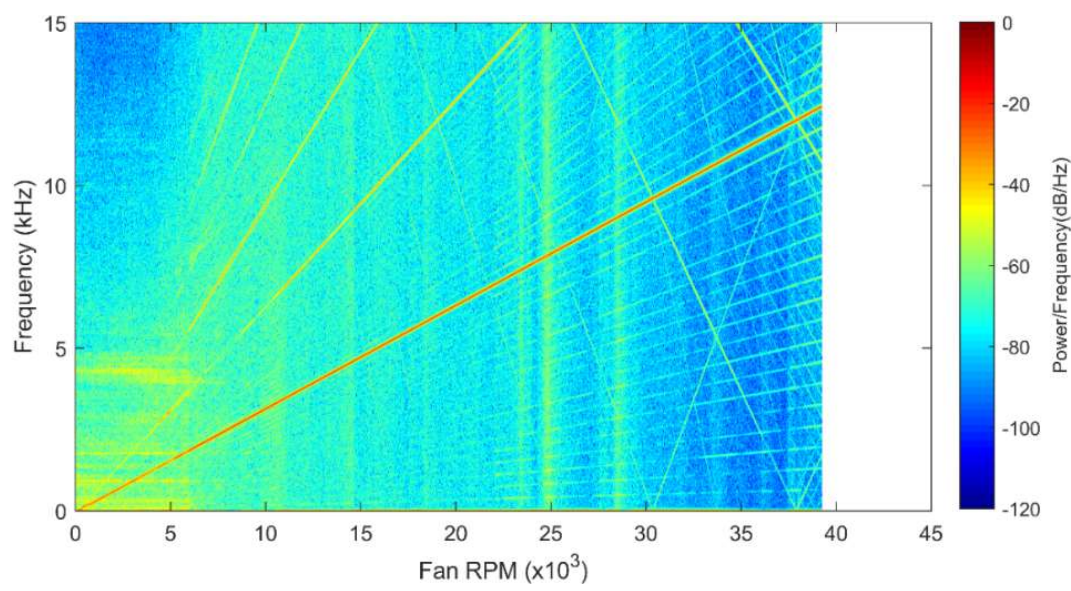

a)

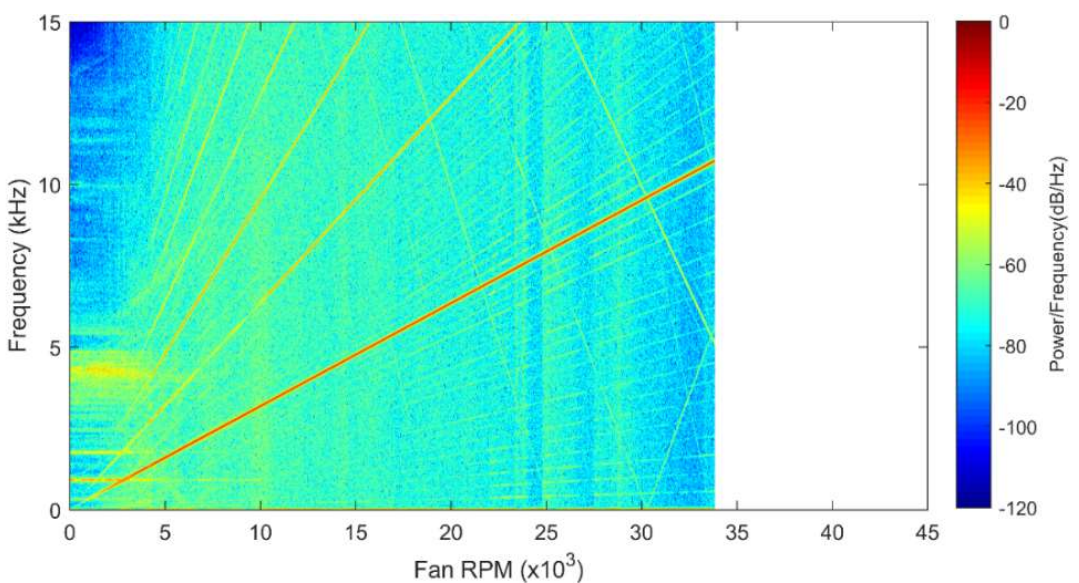

b)

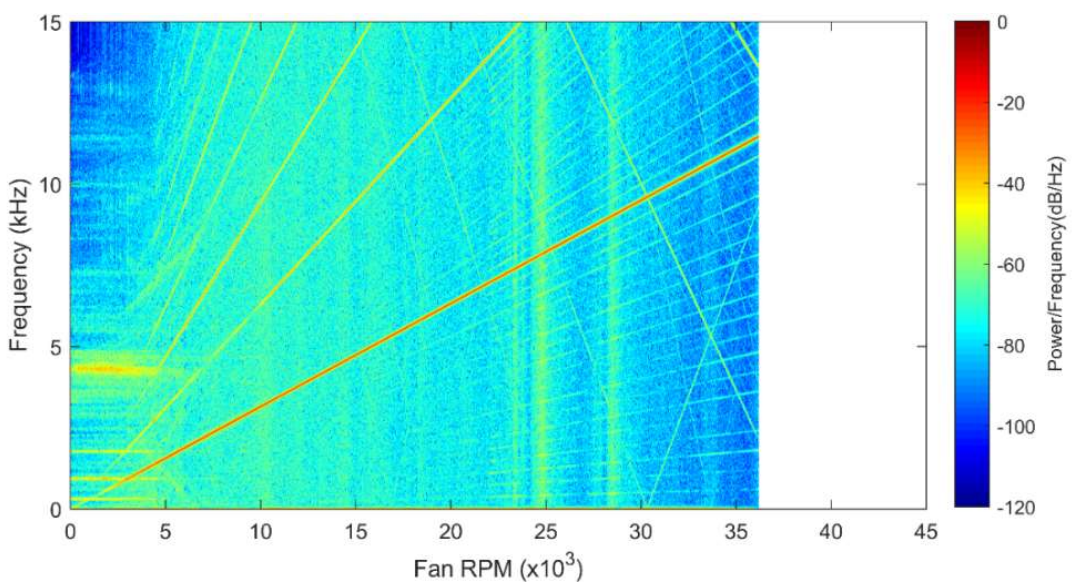

Fig. 13 Microphone spectrogram plotted against RPM for a) RUN094, b) RUN071 and c) RUN112. 


\section{Flow Surveys Using 7-Hole Probe System}

More than 50 separate flow surveys were completed during the EMPAS wind-tunnel tests, using the new AteAEROTECH traverser fitted with the 7-hole pressure probe, for combinations of Mach number, yaw and fan speeds up to 42000RPM. Use of continuous motion traversing meant a flow survey typically required about 12 minutes and approximately 70,000 data points were acquired per survey. Unlike the rakes, communications with the 7HP proved to be very robust throughout the entire test schedule.

Analysis of the flow survey data required various stages of post-processing, to integrate the 7HP pressures with the positioning data from the traverser. Firstly, correction was required to account for a much lower rate of update of the positional information from the traverser arm, compared to the available 7HP pressure data. In particular, for each constant X plane survey, the existing $(\mathrm{Y}, \mathrm{Z})$ values, which were recorded at approximately $1-2 \mathrm{~Hz}$, were interpolated up to $100 \mathrm{~Hz}$, to provide an estimate of the continuous traverse locations matching the $100 \mathrm{~Hz} 7 \mathrm{HP}$ pressure data. Next, the traverser was moving at approximately $20 \mathrm{~mm} / \mathrm{s}$ during the surveys, meaning the $7 \mathrm{HP}$ was acquiring data at approximately 5 values per $\mathrm{mm}$. Hence, the position corrected pressure data was averaged over 25 samples, corresponding to intervals of up to $5 \mathrm{~mm}$ separation (or 1.35 times the probe sting diameter). Finally, these averaged pressure values were then converted into velocity components, based upon the low speed calibration of the 7HP.

During some initial continuous motion flow surveys, the newly developed traverser strayed off the target path, resulting in a situation where the number of measurements in some regions of the field are less dense than normal or are missing. This is apparent in one of the cross-flow velocity vector plots presented later, however these issues were subsequently resolved as shown in all other surveys.

Figure 14 shows the EMPAS wind tunnel model and highlights the blunt base in the region of the strut, at the wing-strut interface and behind the pylon. The figure also shows the tail cone, which has an open end to allow air cooling through the motor. Each of these bluff regions are likely to result in separated and decelerated flow, so this was anticipated to potentially be visible within the survey data.

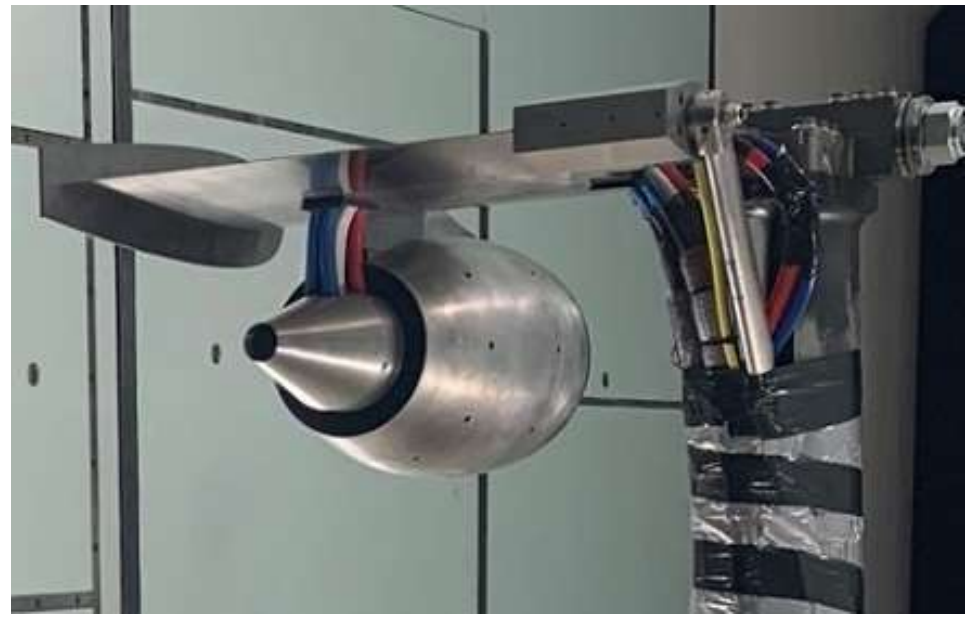

Fig. 14 EMPAS model showing blunt end at the wing-strut and pylon-nacelle junctions.

Three cases, listed in Table 3, will be presented to investigate the flow downstream of the model and specifically the efflux from the engine simulator. The first two cases will be plotted at the three longitudinal stations shown in figure 10, while the third case considers the effect of model yaw angle and only results for the mid longitudinal station are presented for brevity.

Table 3 Flow Survey Cases

\begin{tabular}{ccccc} 
Case & Freestream $M$ & Yaw $\beta^{\circ}$ & $R P M$ & $X$-location $(\mathrm{mm})$ \\
\hline 1 & 0.3 & 0 & 29000 & $57,700,1540$ \\
2 & 0.3 & 0 & 42000 & $57,700,1540$ \\
3 & 0.26 & -10 & 42000 & 700 \\
\hline
\end{tabular}


Figure 15 shows local flow speed, relative to the freestream speed, for Case 1, 29000RPM. The outline of the EMPAS exit nozzle, including the bifurcation, is shown. The location of the wing trailing edge and the endplate is also shown and can be compared with the model geometry seen in figure 14.

The core of the engine simulator efflux is clearly visible and has not expanded greatly between the first two longitudinal stations. The effect of the blunt pylon is apparent at the station closest to the model, indicated by the lower flow speeds observed in the upper quadrant. The core of the efflux is also seen to have rotated slightly, although the orientation of this rotation is in an opposite sense to the fan rotation (fan rotates anti-clockwise here). The result at the third station has a less well defined and perhaps a more turbulent nature. All three stations show reduced flow speeds behind the strut and strut-wing junction as expected.
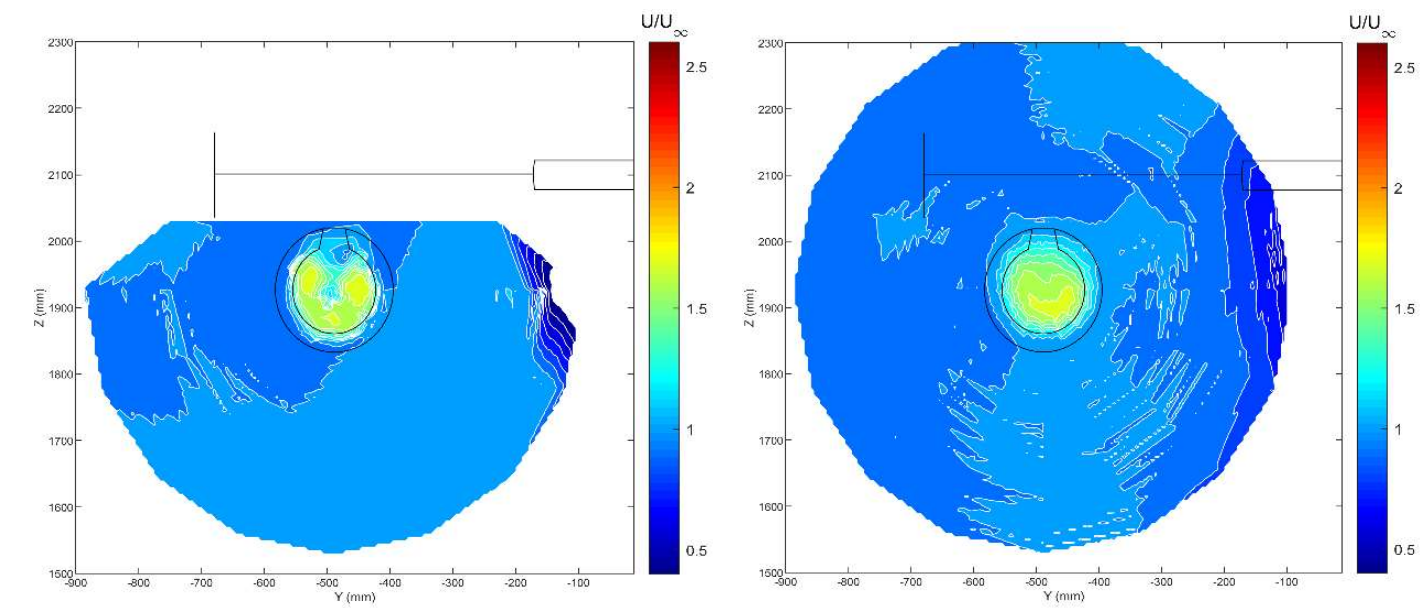

a)

b)

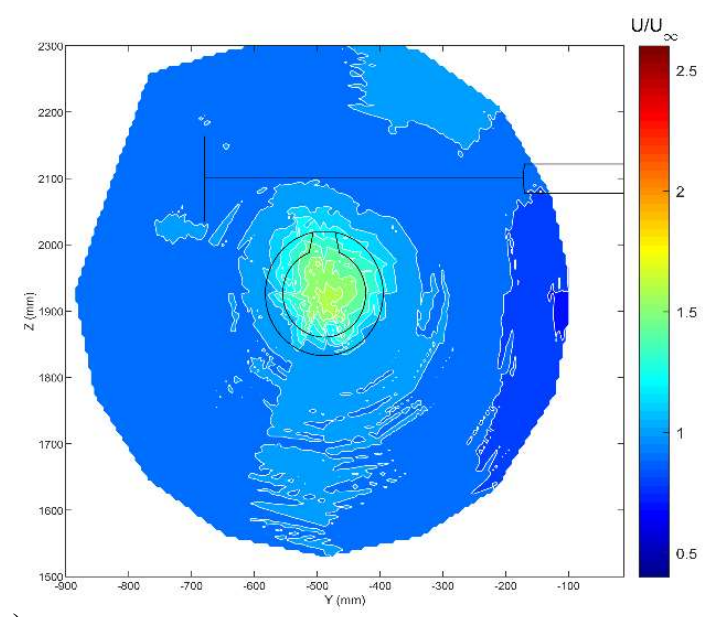

c)

Fig. 15 Non-dimensional flow speed for Case 1 at $M=0.3, R P M=29000$ for longitudinal stations a) $57 \mathrm{~mm}$, b) $700 \mathrm{~mm}$ and c) $1540 \mathrm{~mm}$ behind the tail cone.

Figure 16 shows cross-flow $v$-w velocity vectors for the three longitudinal stations. All stations use the same scaling of the velocity vectors. The first station shows the flow within the core of efflux has little distinct swirl, with the magnitude of velocity vectors generally being similar to levels observed outside of the efflux. The tail cone will result in cross-flow velocity vectors as the efflux tapers inwards. The flow which passes around the external lines of the nacelle has perhaps a more noticeable effect and will also lead to the flow tapering inwards. These effects are greatly diminished at the second and third stations, with the flow straightening. 
Figure 17 shows velocity vectors plotted over approximate horizontal and vertical planes centered around the nozzle. The gradual expansion and weakening of the efflux can be seen with increasing longitudinal extent.

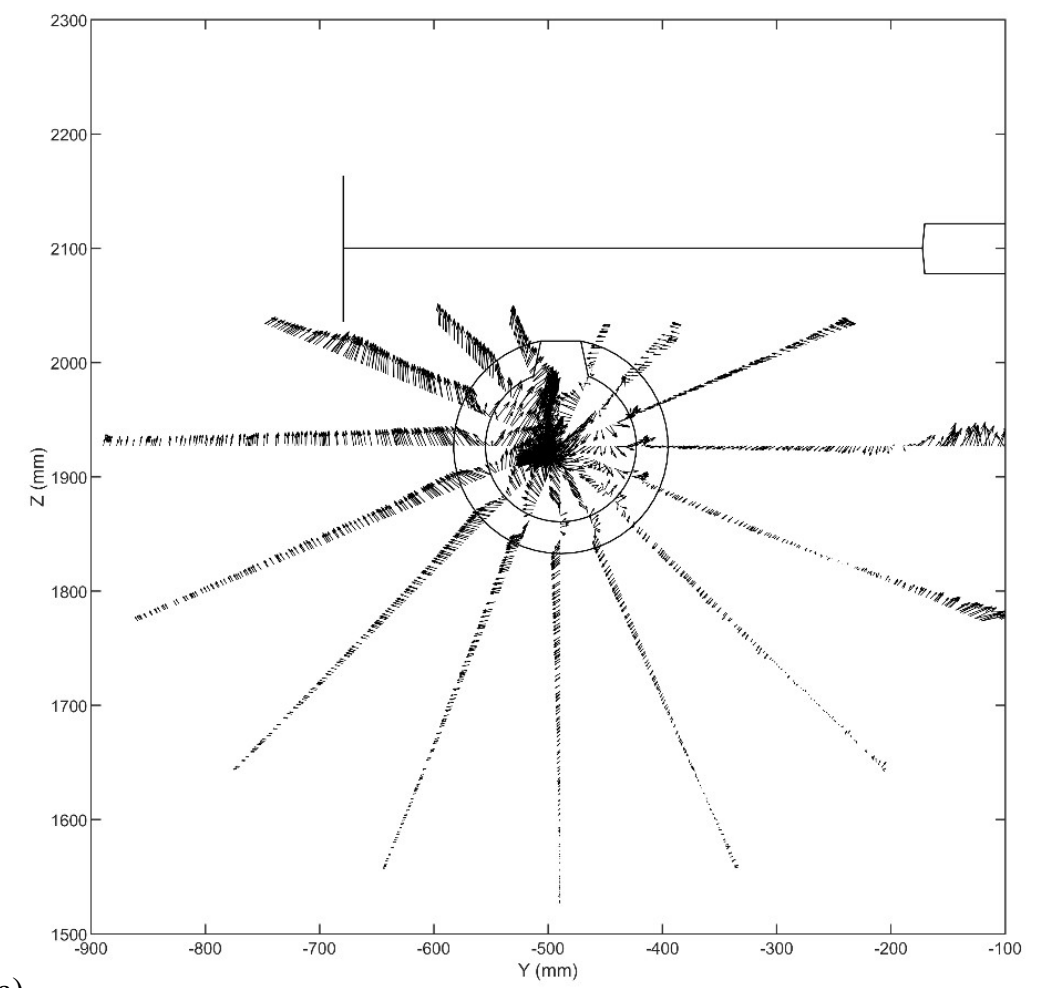

a)

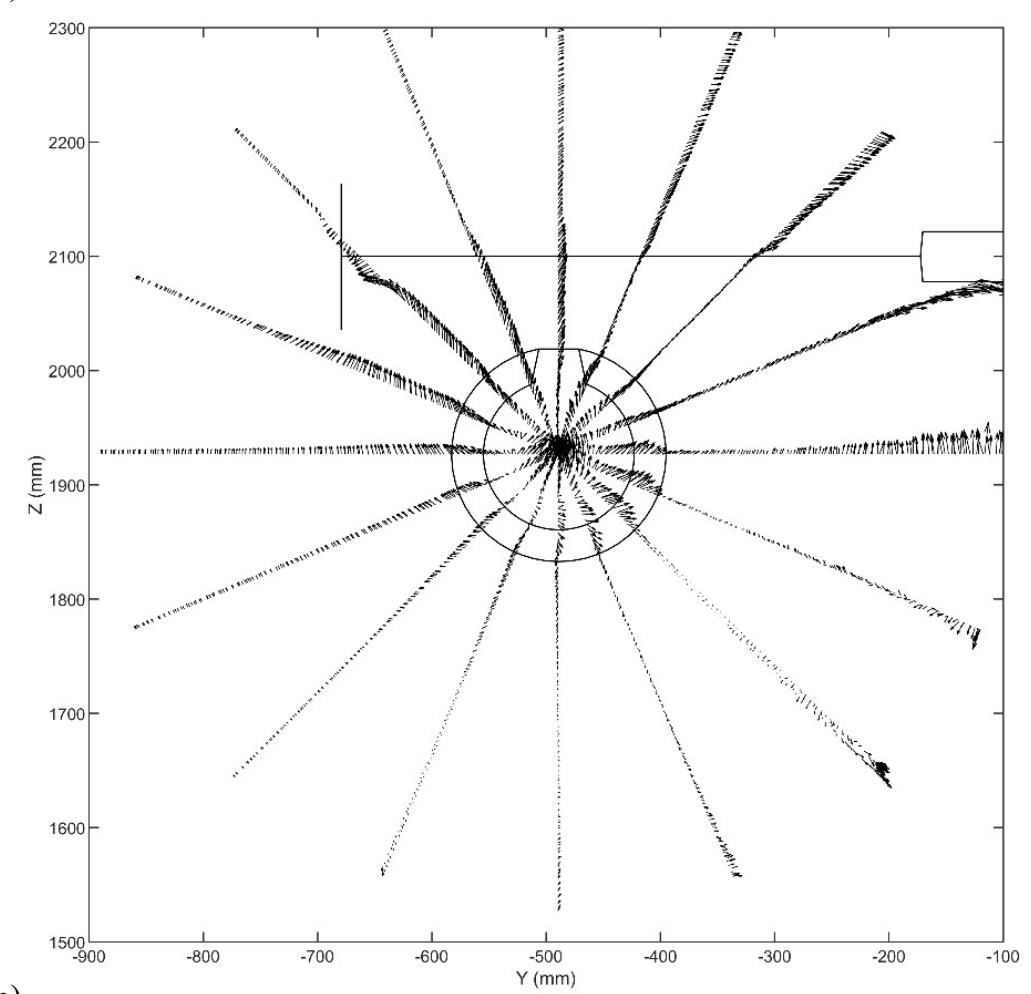

b) 


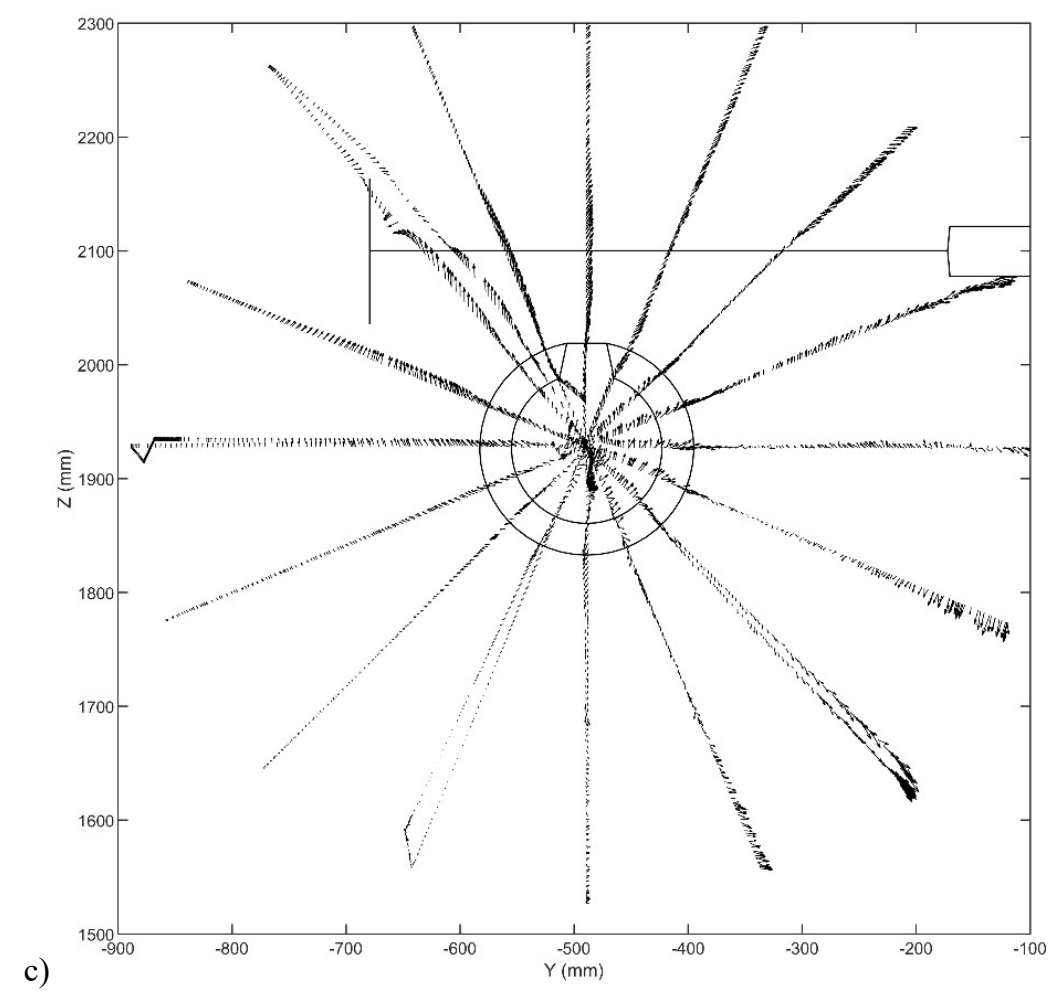

Fig. 16 Cross-flow velocity vectors for Case 1 at longitudinal stations a) $57 \mathrm{~mm}$, b) $700 \mathrm{~mm}$ and c) $1540 \mathrm{~mm}$.

a)
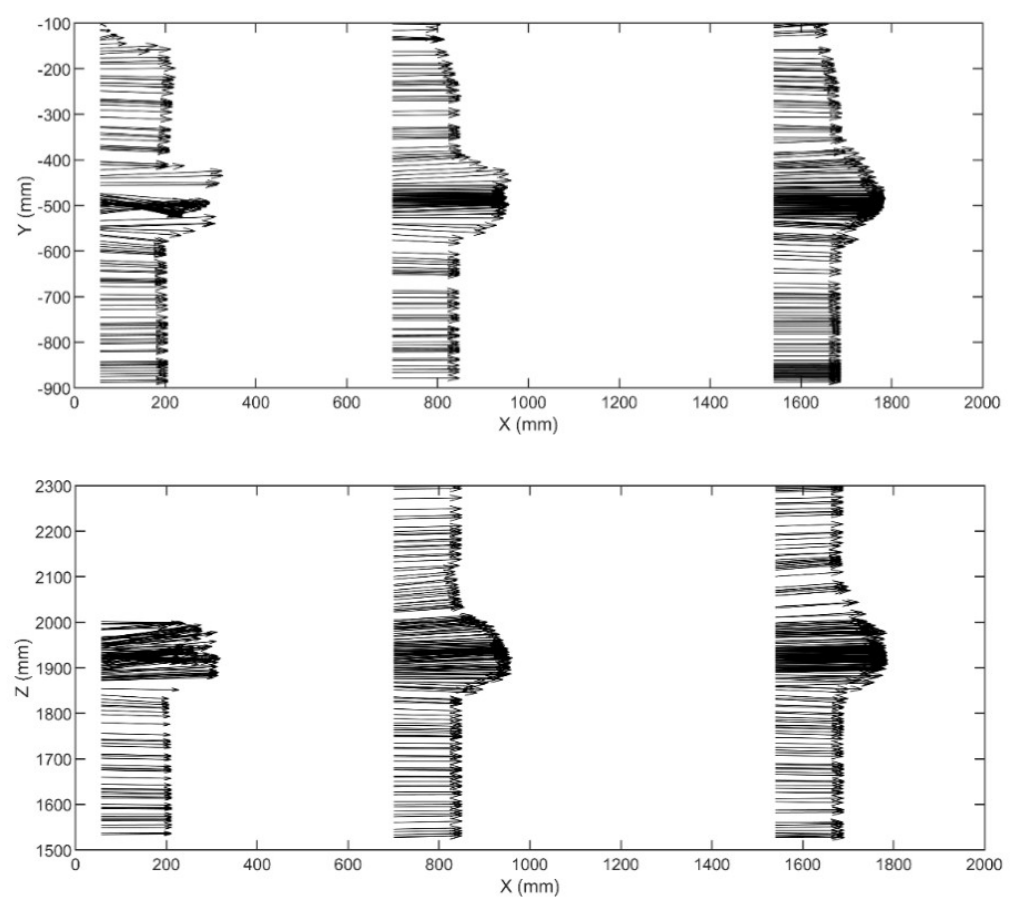

Fig. 17 Velocity vectors centered around nozzle for Case 1 over a) horizontal plane b) vertical plane. 
Figure 18 shows local flow speed for Case 2 at the higher fan speed 42000RPM. The core of the engine simulator efflux, together with the effect of the blunt pylon, is clearly visible at the first longitudinal station. The second station shows a downward displacement of the peak speed location in the efflux core. It was initially considered that the recorded values for $(\mathrm{Y}, \mathrm{Z})$ could be in error, but further investigation suggested this is not the case. It is thought this effect is a consequence of the decelerated flow behind the blunt pylon reducing the strength of upper portion of the efflux, leading to a potentially false impression that the efflux is actually pointing slightly downwards. Unlike Case 1 , the result at the third station still has a well-defined efflux with a gentle expansion.
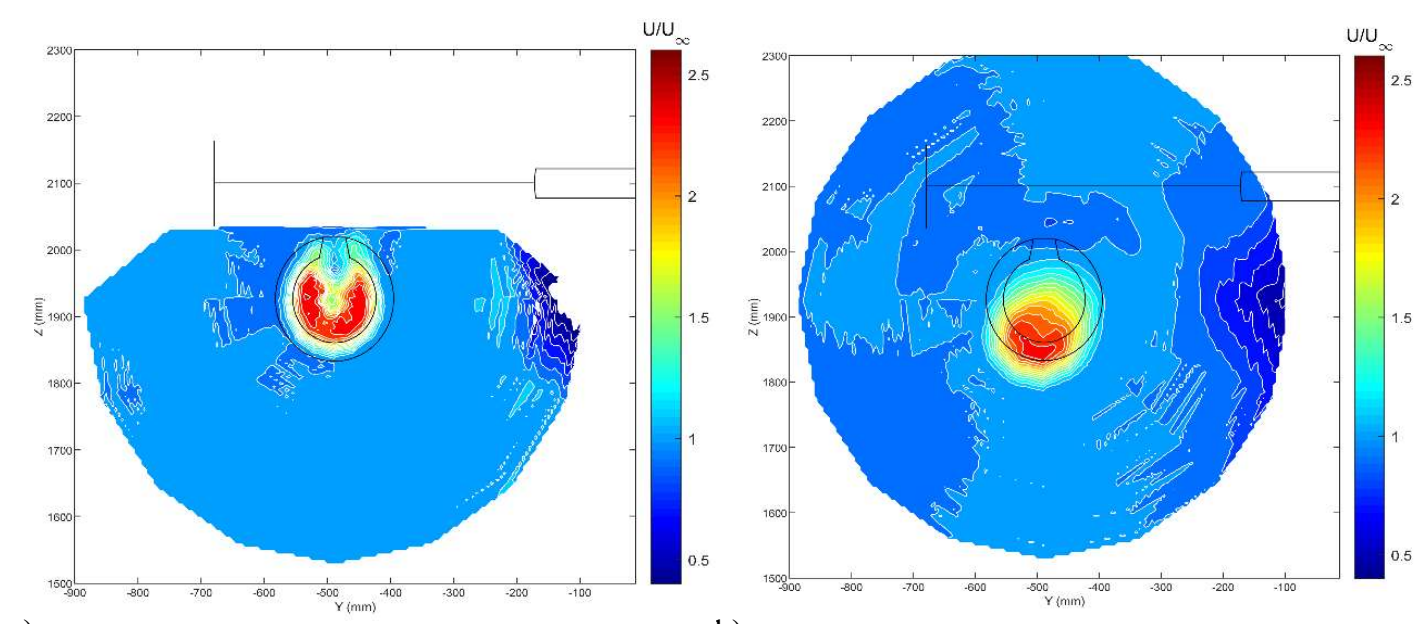

a)

b)

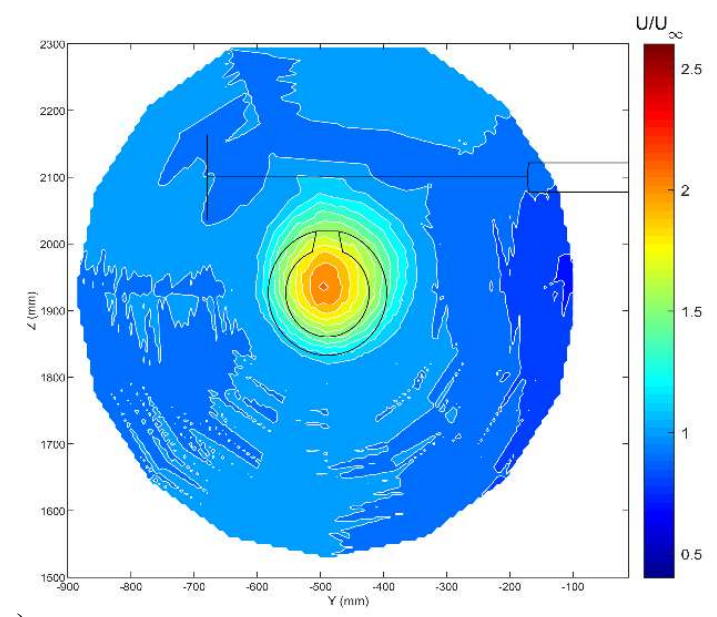

c)

Fig. 18 Flow speed for Case 2 at $M=0.3, R P M=42000$ for longitudinal stations a) $57 \mathrm{~mm}$, b) $700 \mathrm{~mm}$ and c) $1540 \mathrm{~mm}$ behind the tail cone.

Figure 19 shows cross-flow $v-w$ velocity vectors for Case 2 at the three longitudinal stations. The first station shows large variation in the flow field velocities within the core of the efflux, with some indication of low levels of swirl in the direction of the fan rotation. Outside of the efflux, there is again what appears to be a larger impact on cross-flow vectors resulting from the flow around the external lines of the nacelle. These effects are again greatly diminished at the second and third stations. The final station shows an example of the traverser veering off the planned path for a single 'spoke' of the survey in the upper quadrant. The effect of the end plate can be seen in each of the stations, suggesting the possible presence of a tip vortex.

Figure 20 shows velocity vectors plotted over approximate horizontal and vertical planes centered around the nozzle. The gradual expansion and slight weakening of the efflux can be seen, particularly for the upper half of the 
efflux in figure 20b, which may further explain the downward shift of the peak speed seen in figure $18 \mathrm{~b}$. Overall the efflux mainly retains its peak velocities over all the longitudinal stations.

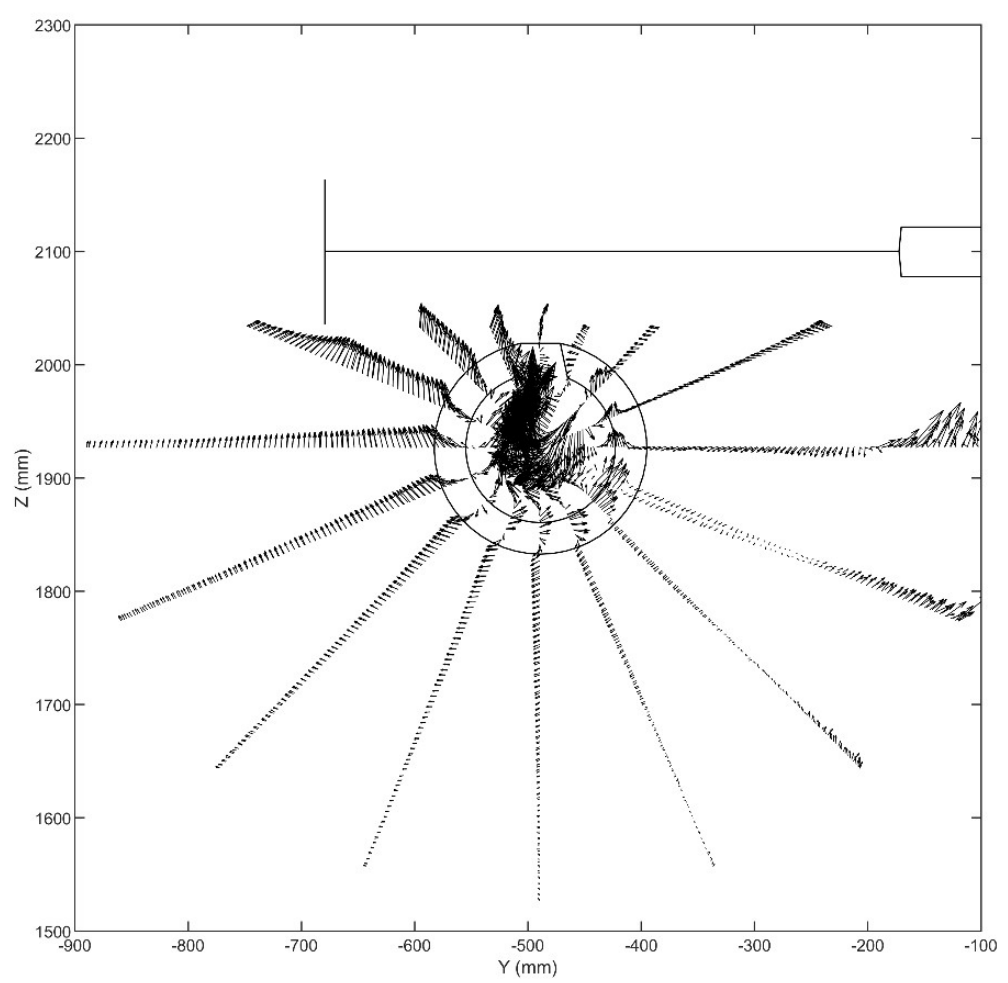

a)

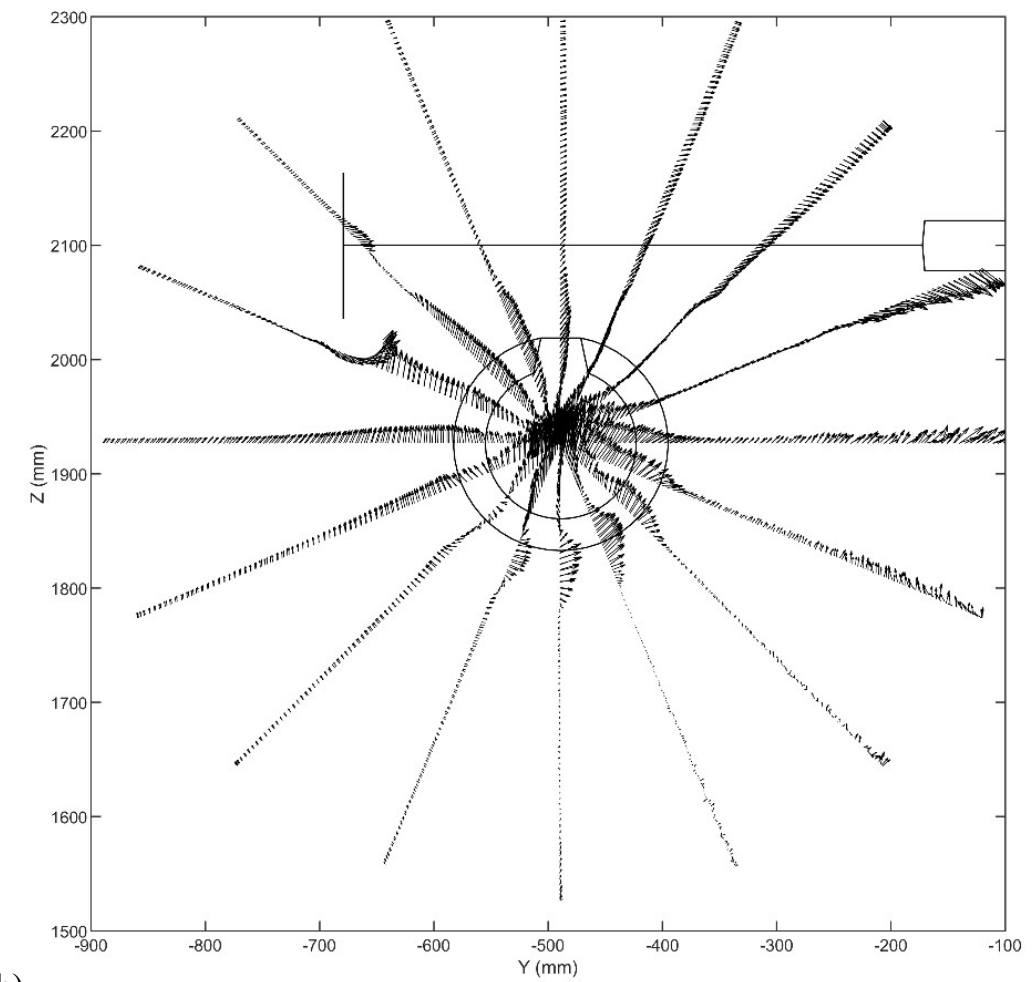

b) 


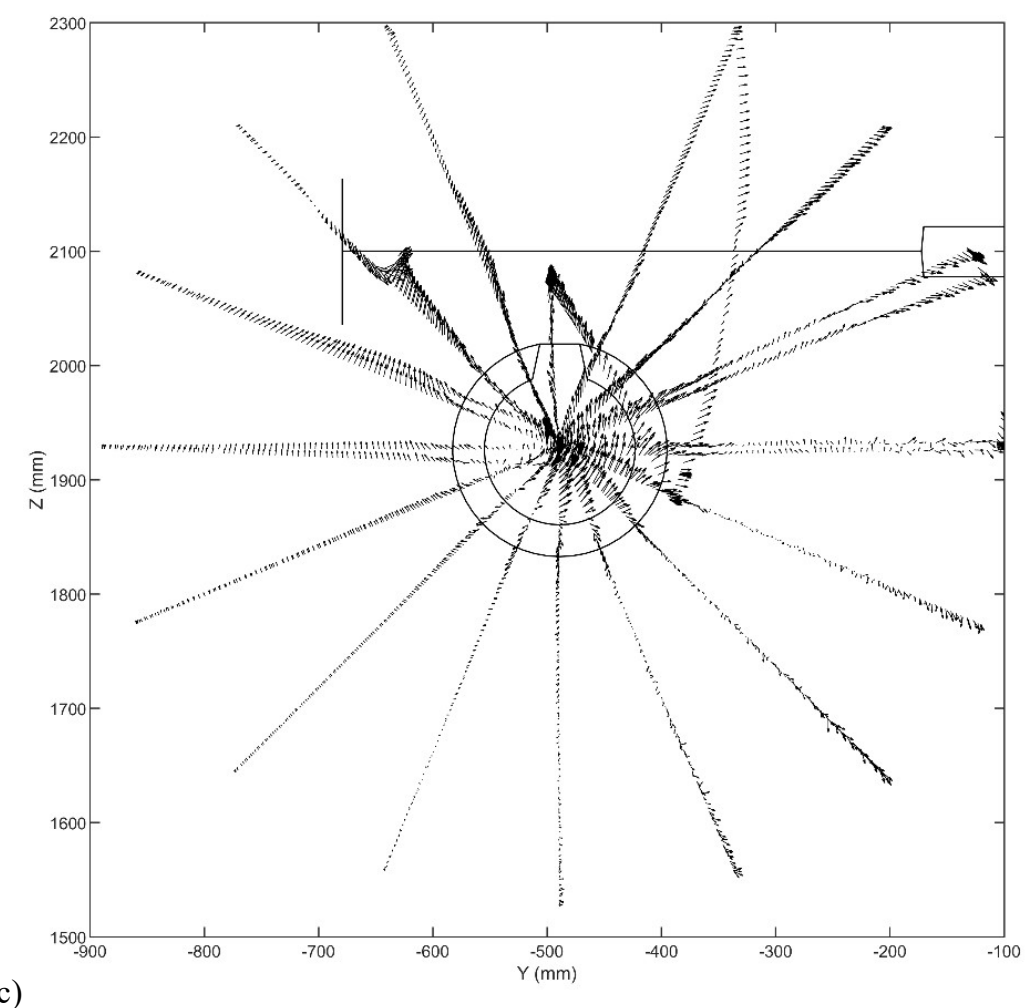

Fig. 19 Cross-flow velocity vectors for Case 2 for longitudinal stations a) $57 \mathrm{~mm}$, b) $700 \mathrm{~mm}$ and c) $1540 \mathrm{~mm}$.

a)
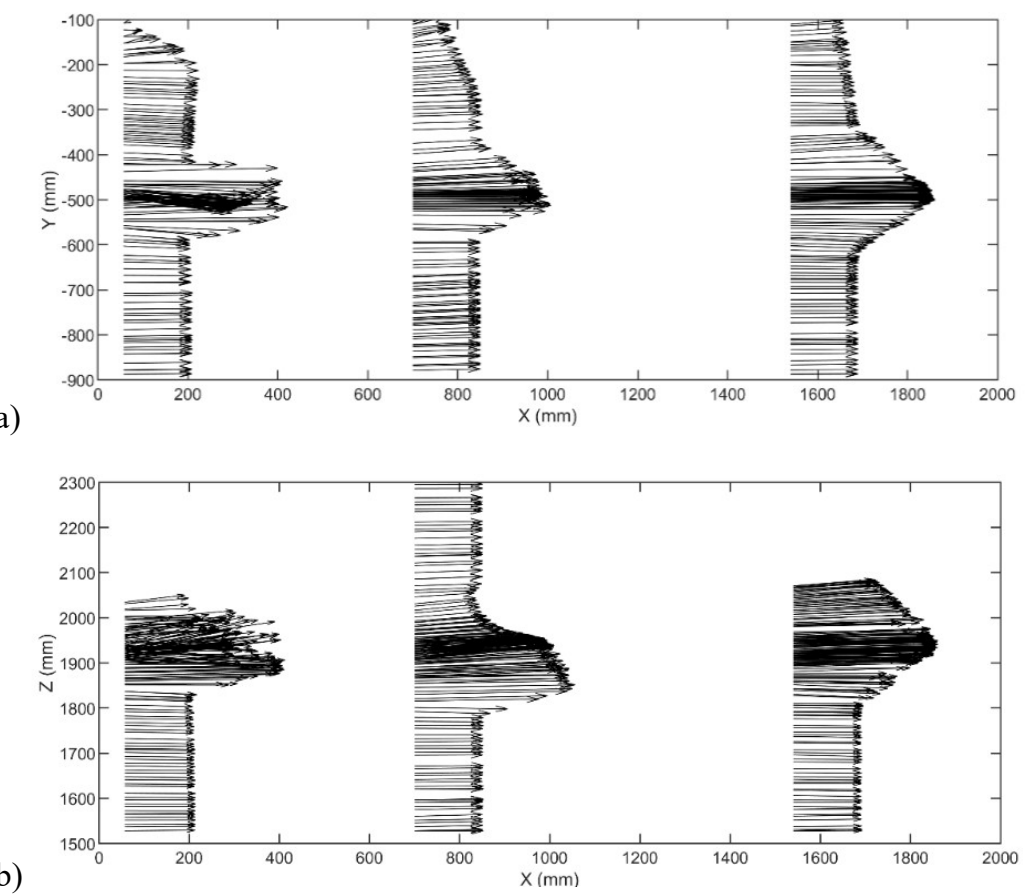

Fig. 20 Velocity vectors centered around nozzle for Case 2 over a) horizontal plane b) vertical plane. 
Figure 21 shows local flow speed for Case 3, for which the model was yawed by 10 degrees with a fan speed of 42000RPM. The yawing of the nacelle steers the efflux outboard, as expected, but the strength of the efflux is similar to the situation shown in figure $18 \mathrm{~b}$, which is also at the same longitudinal station and fan speed but without yaw. The location of peak speed is shifted slightly downward, which is similar to the shift seen in figure $18 \mathrm{~b}$.

The velocity vectors shown in Figure 22 confirm the direction of the efflux is pointing outboard, which provided a useful confirmation for the orientation of velocity vectors given that the probe was calibrated after the EMPAS test results had been obtained.

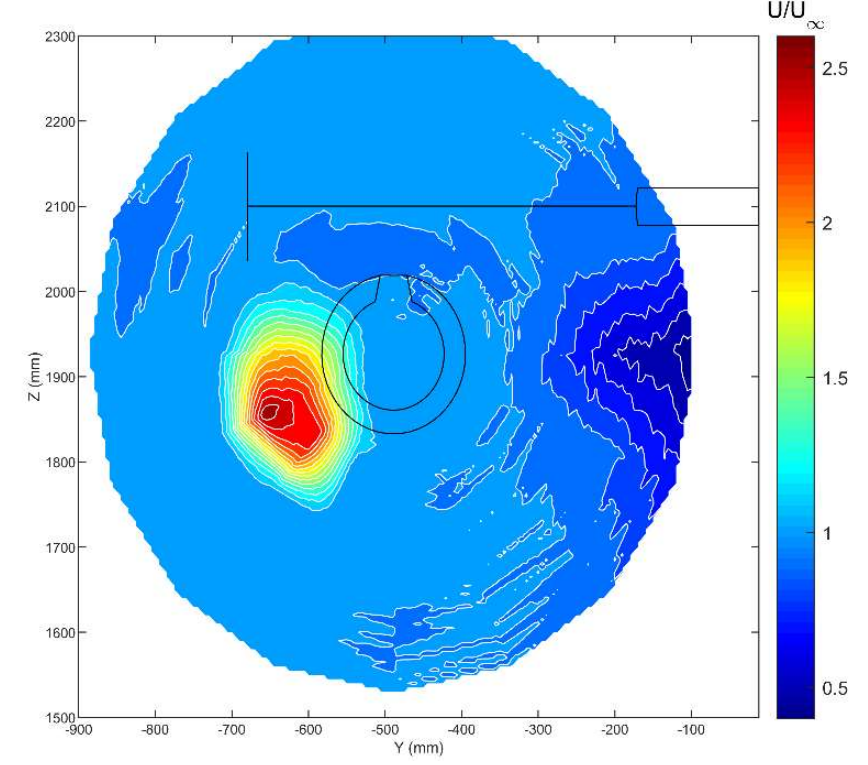

Fig. 21 Flow speed for Case $3, M=0.3, \beta=-10^{\circ}, R P M=42000$ for longitudinal station $700 \mathrm{~mm}$.

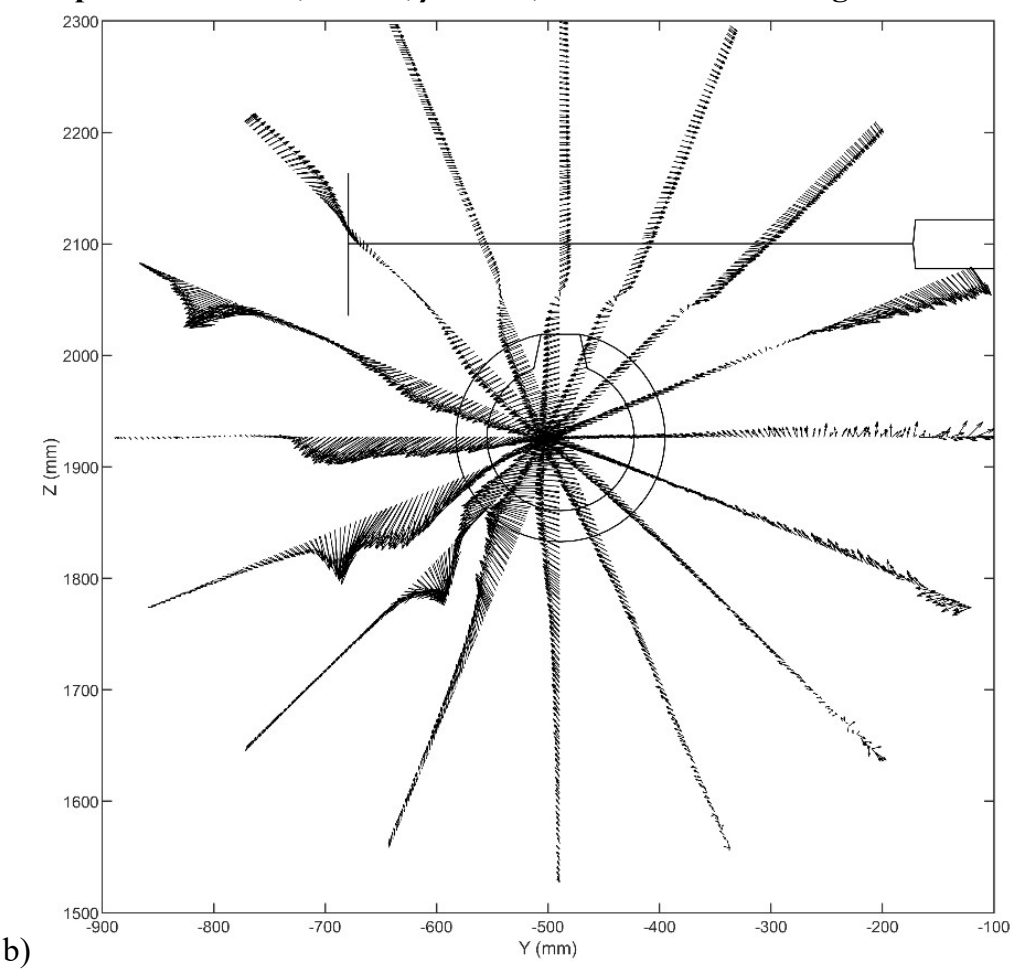

Fig. 22 Cross-flow velocity vectors for $M=0.3, \beta=-10^{\circ}$, $R P M=42000$ for longitudinal station $700 \mathrm{~mm}$. 


\section{V.Conclusions}

As part of the Electric Motor Powered Aero-engine Simulator (EMPAS) project, several differing approaches for flow measurement and system monitoring have each been successfully demonstrated during 3 weeks of testing in the QinetiQ 5-metre wind-tunnel.

In spite of limitations experienced with the robustness of communications with the pressure rakes, the system met its primary requirement to allow fan pressure ratio to be derived over a range of fan and tunnel operating conditions. This in turn has helped to confirm that the EMPAS system has largely achieved its target level of performance during testing.

The use of very low cost microphones proved to be both accurate and robust for direct monitoring of the fan to determine RPM. In addition, there is promising indications that the approach can provide greater insights into the behavior/health of the fan, though further research will be required.

Use of a 7-hole probe, in combination with the Ate-AEROTECH traverser, enabled over 50 separate flow surveys to be collected during wind-tunnel testing. The combination of continuous motion traversing and robust, high speed data acquisition enabled efficient use of tunnel time. Analysis of flow survey data has allowed details of the efflux generated by the EMPAS unit to be investigated, together with the interaction between the efflux and the flow about the rest of the model.

\section{Acknowledgements}

Work completed by the University of Surrey as part of the EMPAS project was funded by ATI/Innovate UK and the University of Surrey. The authors wish to thank the staff from Ate-AEROTECH for their significant help in providing a solution to ensure the rakes could communicate with their data acquisition system, together with development of the traverser which allowed Surrey to demonstrate a 7HP in the QinetiQ 5-metre wind-tunnel. Significant thanks go to the engineering staff, technicians and workshop staff at QinetiQ, for installation of the Surrey instrumentation into the EMPAS model. Each of the project teams at QinetiQ, Boeing, Collins Aerospace and AteAEROTECH deserve thanks for their shared commitment and unwavering enthusiasm to ensure the success of EMPAS. Finally, thanks go to staff within the Surrey EnFlo lab, particularly Paul Nathan and Allan Wells, together with several project students, for their contributions ahead of the EMPAS project, which helped to establish technologies which have now been successfully used in the EMPAS system.

\section{References}

[1] Pembery, M., Doherty, J., Mower, R., Jorgens, C., and Hayes-McCoy, D., "Electric Motor Powered Aero-engine Simulator (EMPAS)," in proceedings of Royal Aeronautical Society - The Future of Aerodynamics, Bristol, UK, July 2018.

[2] Pembery, M., Smith, I., "Electric Motor Powered Aero-engine Simulator EMPAS, Project Introduction and Overview", AIAA Paper (not yet published).

[3] Jorgens, C., "Electric Motor Powered Aero-Engine Simulator (EMPAS): Test Model Hardware Design and Fabrication", AIAA Paper (not yet published).

[4] Mower, R.R., Hogsden, L., Richardson, D., "Controlling and Collecting Data from an Electric Motor Powered Aircraft Simulator (EMPAS)", AIAA Paper (not yet published).

[5] Jorgens, C., "Electric Motor Powered Aero-Engine Simulator (EMPAS): Technology Validation Test Summary and Results", AIAA Paper (not yet published).

[6] Surrey Sensors Ltd., http://surreysensors.com/.

[7] Shaw-Ward, S., Titchmarsh, A., and Birch, D. M., "Calibration and Use of n-Hole Velocity Probes," AIAA Journal, 53(2), 336-346, 2015, DoI 10.2514/1.J053130.

[8] Shaw-Ward, S., McParlin, S. C., Nathan, P., and Birch, D. M., "Optimal Calibration of Directional Velocity Probes," AIAA Journal, 56(7), 2594-2603, 2018, DoI 10.2514/1.J056762. 